\title{
JARDINS VERTICAIS: POTENCIALIDADES PARA O AMBIENTE URBANO
}

\author{
Minéia Johann Scherer (UFRGS, Brasil) mineiaarq@gmail.com \\ Beatriz Maria Fedrizzi (UFGRS, Brasil) beatrizfedrizzi@gmail.com
}

Resumo: $O$ acelerado crescimento das cidades, com intensificação do uso e ocupação do solo, está levando a uma diminuição das áreas disponíveis para a vegetação, sendo visíveis as perdas de qualidade ambiental. A presença de espaços vegetados favorece um microclima agradável e minimiza os efeitos da ilha de calor urbana. Na escala da edificação, a vegetação pode contribuir para o conforto térmico, reduzindo a necessidade de sistemas de climatização artificial. Os benefícios estéticos e psicológicos também representam uma importante justificativa para o aumento do verde, uma vez que o bem estar do homem está intimamente ligado ao seu contato com a natureza. Desta forma, este artigo tem como objetivo discutir as potencialidades do uso dos jardins verticais como um novo suporte a ser explorado para ampliar as áreas urbanas vegetadas. A metodologia do trabalho está baseada em revisão bibliográfica sobre o tema, na qual são apresentadas diferentes tipologias de jardins verticais, bem como, exemplos realizados utilizando uma das técnicas, as chamadas cortinas verdes, a qual se destaca por também assumir a função de elemento de proteção solar para a edificação. Os resultados demonstram o grande potencial dos jardins verticais para a economia de energia, além dos benefícios sociais, psicológicos e de qualificação dos ambientes de trabalho.

Palavras-chave: Jardim vertical. Cortinas verdes. Proteção solar. Conforto térmico. Sustentabilidade.

\begin{abstract}
The rapid growth of cities, with increased use and soil occupation, is leading to a decrease in available areas for vegetation being visible losses of environmental quality. The presence of vegetated promotes a microclimate and minimizes the effects of urban heat island. On the scale of the building, vegetation can contribute to thermal comfort, reducing the need for artificial climate control systems. The aesthetic and psychological benefits are also an important reason for the increase in green areas, considering that human is closely linked to his contact with nature. Thus, this article aims discusses the potential use of vertical gardens as a new support to be explored to increase vegetated urban areas. The work methodology is based on bibliographical review about the subject, which presents different types of vertical gardens as well, examples performed using one of the techniques, called green curtains, which stands out by also assume the function of element sun protection for the building. The results demonstrate the great potential of vertical gardens for energy savings, as well as social, psychological and qualification of the workplace benefits.
\end{abstract}

Keywords: Vertical Garden. Green curtains. Sunscreen. Thermal comfort. Sustainability. 


\section{Introdução}

Os impactos decorrentes da urbanização acelerada estão sendo sentidos em diferentes aspectos, o que leva à degradação ambiental das nossas cidades e, conseqüentemente, à diminuição da qualidade de vida dos cidadãos. Um dos pontos de maior relevância é a escassez de áreas vegetadas no meio urbano, cada vez mais dominado por edifícios e pavimentações. Mesmo sendo de amplo conhecimento os benefícios da vegetação para a qualificação ambiental e a sustentabilidade, nos deparamos com a intensificação de uso e ocupação do solo urbano, desordenado e seguindo principalmente critérios econômicos. As áreas destinadas ao verde são reduzidas aos índices mínimos previstos no lote e praticamente inexistem novas áreas que possam ser contempladas com praças ou parques. Isto, além de limitar o importante contato do ser humano com a natureza, influencia no conforto ambiental das cidades, alterando o seu microclima e intensificando o fenômeno da ilha de calor urbano.

A ilha de calor ocorre nos centros urbanos devido à grande concentração de edificações e superfícies pavimentadas, que absorvem, retém e refletem mais energia solar do que superfícies vegetadas. Deste modo, a temperatura do ar tende a elevar-se, modificando as condições climáticas naturais do local. A presença da vegetação, em uma proporção compatível com as áreas construídas, é, portanto, uma importante estratégia para manutenção do conforto térmico das cidades, além de reter partículas de poluição, umidificar o ambiente, reter a água da chuva e modificar a ação dos ventos.
A vegetação contribui para a amenização do microclima devido ao processo de evapotranspiração das espécies vegetais, também chamado de resfriamento evaporativo: a energia do sol é absorvida pela planta, resultando na perda de calor na atmosfera e na umidificação do ambiente. Além disso, o sombreamento causado pela vegetação diminui as temperaturas superficiais dos pavimentos e fachadas das edificações, uma vez que intercepta grande parte da radiação solar incidente (LYLE, 1994; CANTUÁRIA, 1995; DE LA TORRE, 1999; MASCARÓ: MASCARÓ, 2005).

Diante da constatação de que o crescimento acelerado das grandes cidades está levando a um esgotamento das áreas públicas disponíveis para implementação de novos parques ou áreas revegetadas, este artigo propõe o incentivo ao uso dos jardins verticais, ou seja, das superfícies verticais das edificações como novos suportes para desenvolvimento do verde em nossas cidades.

Tendo em vista as recentes técnicas para execução dos jardins verticais e o limitado número de publicações sobre o assunto, especialmente no Brasil, este texto tem como objetivo principal, levar ao conhecimento do leitor as diferentes tipologias de jardim vertical, discutindo suas principais potencialidades para o meio urbano e para as edificações. Após, o foco é direcionado para uma tipologia específica de jardim vertical, as chamadas cortinas verdes, que agregam importante potencial como proteção solar para as fachadas das edificações, apresentando alguns exemplos bem sucedidos 
executados com esta técnica. O estudo aprofundado das cortinas verdes é tema de doutoramento do autor, no Programa de Pesquisa e Pós-graduação em Arquitetura da Universidade Federal do Rio Grande do Sul.

A metodologia do trabalho está baseada em revisão bibliográfica, com levantamento e organização de dados coletados sobre a temática dos jardins verticais e das cortinas verdes.

\section{Classificação dos Jardins Verticais}

A denominação de fachada verde, dos termos em inglês "green wall" ou "green façade", refere-se ao revestimento de alvenarias ou outras estruturas verticais, por meio do desen- volvimento em sua superfície de vegetação auto-aderente ou com auxílio de suportes, nos quais as raízes do vegetal estão na base desta estrutura, em contato direto com o solo ou com outro tipo de substrato (DUNNETT; KINGSBURY, 2004). A partir desta definição geral, podemos classificar diferentes tipos de jardim vertical, sendo que neste trabalho vamos adotar o proposto por Sharp et al. (2008) e Pérez (2010), onde há distinção de basicamente três tipos: os sistemas extensivos tradicionais, as cortinas verdes e o sistema intensivo denominado parede viva (Quadro 1).

QUADRO 1: CLASSIFICAÇÃO DOS JARDINS VERTICAIS

\begin{tabular}{|c|c|c|c|}
\hline & \multicolumn{2}{|c|}{ Sistemas extensivos } & Sistemas intensivos \\
\hline Fachadas verdes & Fachada verde tradicional & & \\
\hline & Dupla fachada verde ou cortina verde & Modular & \\
\hline & & Treliça & \\
\hline & & Com fio ou cabeada & \\
\hline & & Malha & \\
\hline Paredes vivas & Jardineiras perimetrias & & \\
\hline & & & Em vasos ou cavidades \\
\hline
\end{tabular}

Fonte: Adaptado de Pérez, 2010

A diferença dos sistemas extensivos está, basicamente, no plantio de espécies trepadeiras diretamente no solo ou em jardineiras, enquanto que no sistema intensivo não há presença de solo e as espécies, geralmente de pequeno porte, são fixadas em painéis especiais. Sistemas extensivos são, no geral, mais fáceis de construir e demandam pouca manutenção, enquanto que o sistema intensivo tem implantação mais complexa e exige um elevado nível de manutenção posterior.

\subsection{Fachada verde tradicional}

Os sistemas extensivos tradicionais se caracterizam pela presença de espécies trepadeiras auto-aderentes que são capazes de se fixar diretamente nas alvenarias, por meio de raízes 


\section{ReLAInEF}

adventícias ou gavinhas ramificadas, formando um revestimento que remete a uma pele verde na edificação (Figura 1). Algumas das espécies mais comuns são a Parthenocissus tricuspidata (falsa-vinha), Hedera helix (hera-inglesa) e a Ficus pumila (unha-de-gato ou falsa-hera).

A maioria das espécies auto-aderentes tende a crescer em direção à luz, portanto, é preciso observar a posição em que será plantada a muda quando o objetivo é o revestimento de fachadas. É interessante plantá-la na região mais sombreada, pois desta forma seu crescimento naturalmente irá ser direcionado para o restante da superfície (DUNNETT; KINGSBURY, 2004).

\section{FIGURA 1: PELE VERDE DE CRESCIMENTO ESPONTÂNEO E INTEGRADO AO PROJETO AR- QUITETÔNICO}
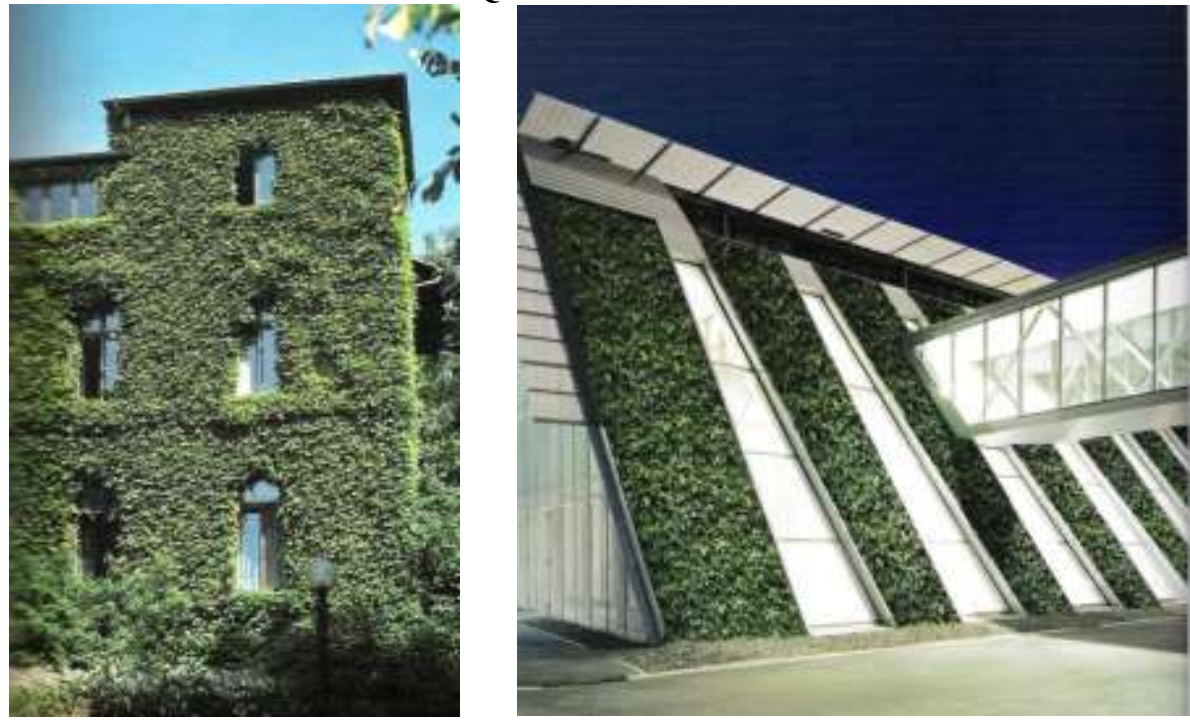

Fonte: KÖHLER, 1993, p. 97 e UFFELEN, 2011, p. 148

\subsection{Cortina verde}

Também denominada dupla fachada verde, são sistemas em que é necessária a instalação de algum tipo de suporte ao longo do qual a vegetação trepadeira irá se desenvolver. Oss uportes podem variar quanto aos materiais usados, ao formato, a distância entre os apoios e também quanto ao afastamento da parede. As espécies propícias são inúmeras, dependendo de cada região. Alguns exemplos para o sul do Brasil são a Lonicera japônica (madressilva), Wisteria SP (glicínia), Thunbergia grandiflora (tumbérgia-azul).

Como já citado, a tipologia denominada cortina verde será exemplificada a seguir, através de exemplos arquitetônicos materializados com esta técnica. A particularidade mais relevante em relação aos outros tipos de jardim vertical é a possibilidade do elemento estar sobreposto às aberturas ou regiões envidraçadas da edificação, e não somente às paredes opacas. Esta é a característica dominante que vai classificar a cortina verde como elemento de proteção solar em arquitetura.

As duas principais subdivisões das cortinas 


\section{ReLAInEF}

verdes são:

Modular: consiste na combinação de módulos metálicos prontos, com jardineira e treliça, fixados na fachada das edificações. Neste caso, a vegetação trepadeira possui uma área de substrato e de crescimento limitada, o que facilita a manutenção (Figura 2).

Treliça: ao contrário do sistema anterior, o plantio das espécies se dá diretamente no solo ou em grandes jardineiras contínuas, o que propicia um desenvolvimento maior da trepadeira. As treliças permitem maior possibilidade de variação nas composições de fachada, na utilização de diferentes materiais e na distância em relação à parede para sua execução (Figura 3).

FIGURA 2: SISTEMA MODULAR COM CONTAINERS, DA EMPRESA GSKY PLANT SYSTENS
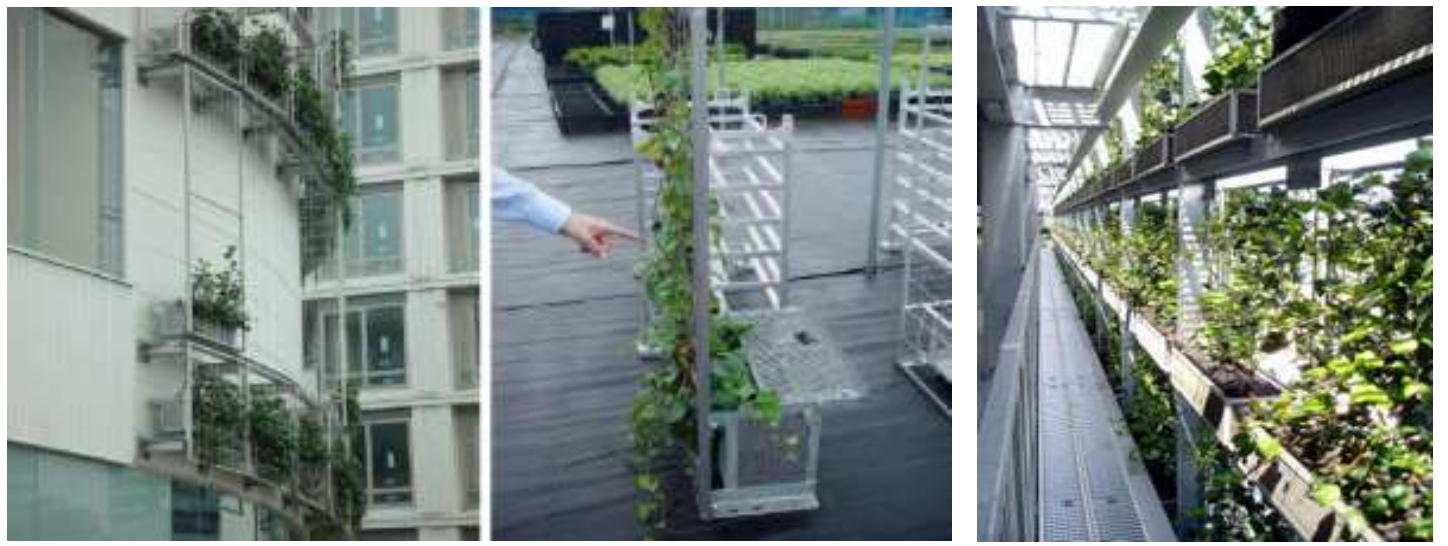

Fonte: GSKY PLANT SYSTENS, 2012.

\section{FIGURA 3: SISTEMA COM TRELIÇA DO EDIFICIO CONSORCIO, SANTIAGO, CHILE, E DO} EDIFÍCO EX-DUCATI, ITÁLIA
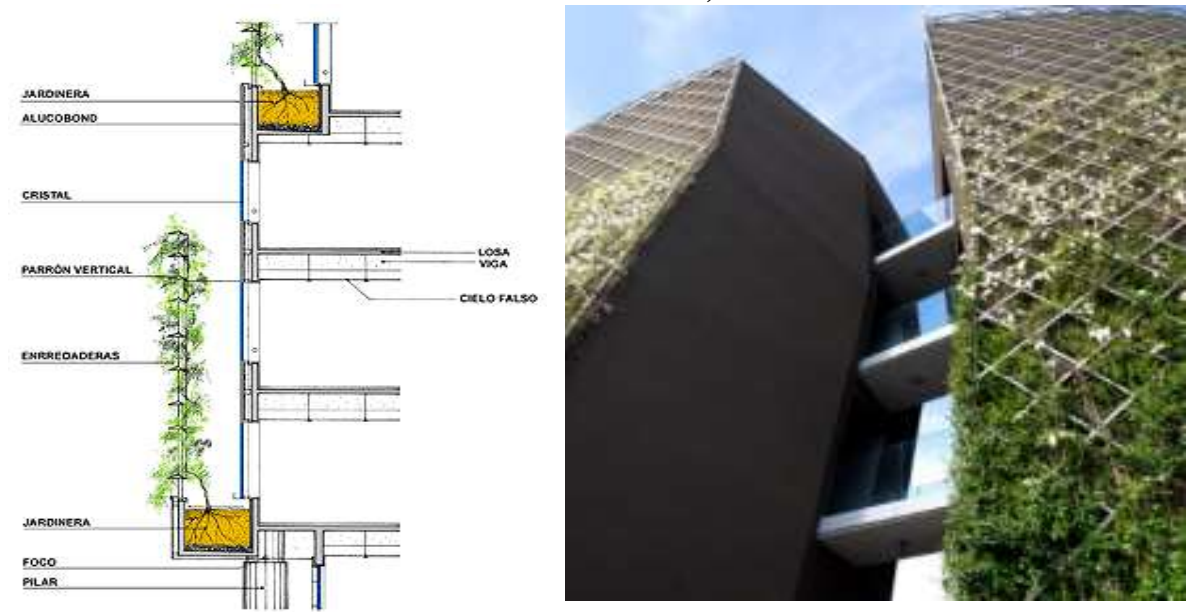

Fonte: ENRIQUE BROWNE Y ASOCIADOS, 2012 e MARIO CUCINELLA ARCHITECTS, 2012.

\subsection{Parede viva}

Também chamado de sistema modular, classi- fica-se como intensivo e diferencia-se dos anteriores por adotar módulos especiais para o desenvolvimento das plantas, sendo constituí- 
dos por painéis geotêxteis, vasos ou blocos com cavidades para o substrato, não havendo contato da raiz da planta com o solo na base da estrutura. Comumente adotam o sistema hidropônico, onde não há substrato, somente irrigação com fertilizantes solúveis.

Podem utilizar uma grande variedade de espécies, geralmente samambaias, bromélias e arbustos de pequeno porte, formando uma parede com grande impacto visual, sendo muitas vezes tratada como obra de arte. Atualmente diversas empresas a nível mundial executam diferentes sistemas de paredes vivas, sendo que a classificação pode ser subdividida em basicamente dois grandes grupos, conforme segue.

Vasos ou cavidades: este sistema utiliza módulos onde, geralmente, a vegetação já está desenvolvida. Um exemplo é o sistema desenvolvido pela empresa Norte Americana GSky Plant System, onde a execução é realizada com a fixação dos módulos a uma estrutura metálica anexada às paredes (Figura 4).

Painéis geotêxteis: a técnica do botânico Patrick Blanc é pioneira e consiste no plantio de arbustos de pequeno porte e forrações ao longo de uma manta geotêxtil fixada e estruturada em uma grelha metálica ou de PVC, sem a presença de solo. Os minerais necessários para desenvolvimento da vegetação são oferecidos durantes as frequentes regas do sistema. Também pode ser aplicado no interior de edificações, desde que exista iluminação, natural ou artificial, suficiente. $\mathrm{O}$ processo de planejamento do painel leva em consideração as características das espécies escolhidas, seu porte e coloração. Já o resultado final depende da velocidade de crescimento das plantas (Figura $5)$.

\section{Potencialidades do uso dos Jardins Verticais}

Assim como as demais formas de aplicação da vegetação no meio urbano, desde a presença de espécies arbóreas em ruas, praças ou parques, até a implementação de telhados verdes, uso já amplamente valorizado, os jardins verticais podem contribuir de forma impactante na qualificação ambiental das cidades e também no conforto térmico das edificações, reduzindo a necessidade de climatização artificial. Peck et al (2007) ressaltam que o efeito dos jardins verticais pode ser superior ao obtido com telhados verdes, principalmente no caso de edifícios com vários pavimentos. Isso porque a área de superfície vertical é geralmente superior e abrange todos os pavimentos e não somente a cobertura. Desta forma, as superfícies verticais representam um vasto território a ser explorado, uma grande oportunidade para aumento da massa vegetal nas cidades.

Na escala da edificação, os diferentes tipos de jardim vertical atuam na melhoria do desempenho térmico das edificações, pela combinação de diversos fatores. As fachadas verdes, com espécies trepadeiras aderentes às paredes, por exemplo, age como um revestimento isolante, capaz de reduzir a energia necessária, tanto para aquecer, como para resfriar os ambientes internos (DUNNETT; KINGSBURY, 2004).

Johnston e Newton (2004) acrescentam que, ao contrário da crença popular, fachadas cobertas 


\section{ReLAInEP}

com vegetação são mais secas, outro fator que reduz a perda de calor por condutividade. A água é absorvida pelas folhas e o excesso escoa até o solo, evitando a penetração até a parede, que permanece seca.

\section{FIGURA 4: SISTEMA COM MÓDULOS FIXADOS EM ESTRUTURA METÁLICA, DA EMPRESA GSKY PLANT SYSTENS}
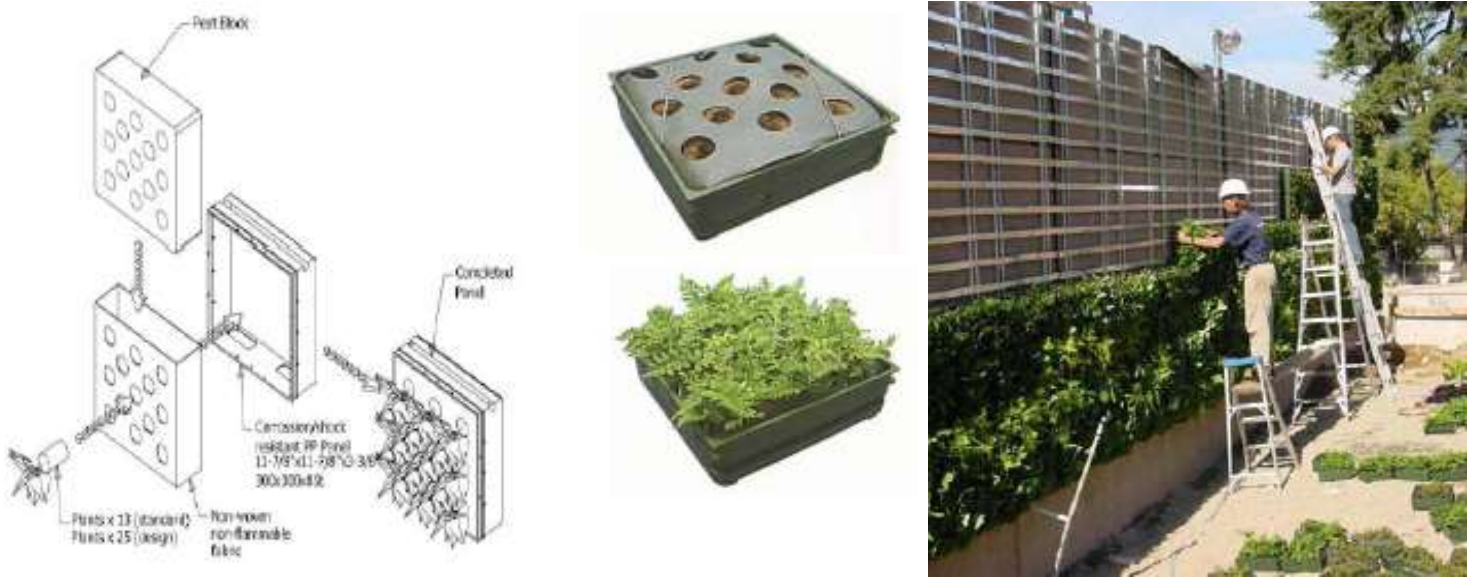

Fonte: GSKY Plant Systens, 2012

\section{FIGURA 5: PROCESSO DE PLANEJAMENTO E EXECUÇÃO DO SISTEMA DE JARDIM VERTI-}
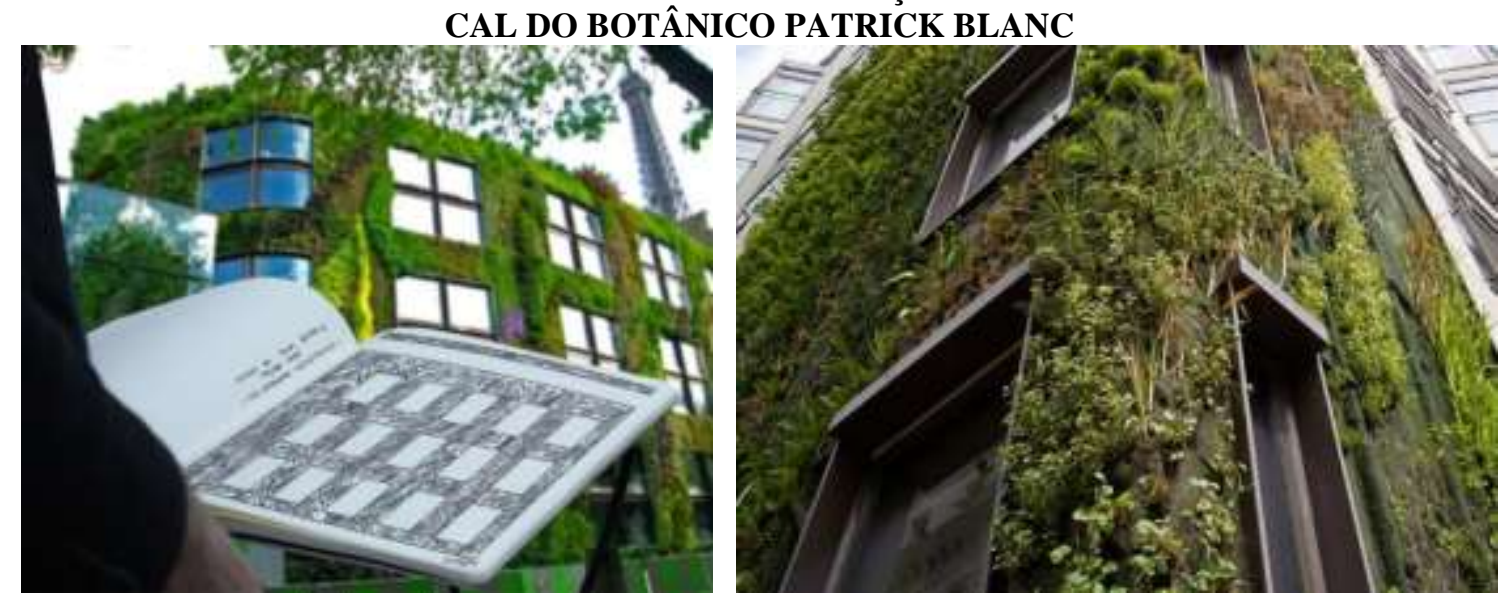

Fonte: Stylepark, 2012

A utilização das cortinas verdes, com espécies trepadeiras afastadas das paredes, por outro lado, atua especialmente no bloqueio da radiação solar direta. Além disso, o processo de evapotranspiração das plantas retira calor e umidifica o ar, realizando naturalmente sua refrigeração antes de chegar ao ambiente interno. Em regiões de clima composto, o ideal é a utilização de algumas espécies caducifólias, para que no inverno o sol atinja a fachada e aqueça os ambientes (JOHNSTON; NEWTON, 2004).

Sobre as espécies caducifólias, Cantuária (1995) comenta sobre a propriedade de adaptação às variações climáticas a curto e longo prazo, já que, de acordo com o ângulo de incidência dos raios solares e a intensidade da temperatura da primavera, as folhas são reor- 
ganizadas, inclinadas ou até mesmo tem seu brotamento antecipado. Dessa forma, a sombra adequada à edificação é fornecida também no momento adequado.

Kwok e Grondzik (2013) complementam a atuação das cortinas verdes com uma constatação surpreendente: o uso da vegetação pode ser mais eficiente que o sombreamento realizado por elementos de proteção solar fixos, tendo em vista o comportamento da vegetação a qual acompanha melhor as variações de temperatura do que os ângulos solares.

Desta forma, pode antecipar sua brotação em um ano em que o aquecimento da primavera começa mais cedo ou vice-versa. Da mesma forma, pode perder antes ou permanecer com as folhas mais tempo, dependendo da condição de início do outono, de maior ou menor necessidade de sombreamento.

Além disso, enquanto os materiais usuais utilizados em proteções solares, como plásticos ou metais, absorvem mais calor aquecendo o ar circundante, a vegetação, ao contrário, resfria o ar pelo processo de evapotranspiração. Isto é mais uma evidência das vantagens no uso da vegetação como elemento de proteção solar.

\section{Edificações com Cortinas Verdes}

Segundo Köhler (2008), o interesse científico pelo uso da vegetação em fachadas e em seu benefício ambiental é relativamente recente. Na Alemanha, no final da década de 1970, eclodiu um movimento para propor mudanças nos paradigmas da arquitetura, onde o uso da fachada verde era visto como alternativa de revestimento para projetos de edifícios ecológicos. Foi reconhecido que as fachadas verdes eram relativamente fáceis de construir e um programa de incentivo foi desenvolvido em Berlin para seu uso. Por este motivo, até poucos anos atrás, a maioria das publicações sobre o assunto restringia-se ao idioma alemão, o que dificultou a difusão e o incentivo para novas pesquisas no resto do mundo.

Mais recentemente, a partir do ano 2000, o botânico francês Patrick Blanc revolucionou a integração entre arquitetura e paisagem, destacando-se no paisagismo atual por suas criações de jardins verticais em edificações.

Atualmente, o uso da vegetação integrada com a fachada da edificação é considerada uma técnica coerente com os princípios de sustentabilidade e de eficiência energética, sendo que existe cada vez mais incentivo e movimentos a nível internacional que tratam deste assunto. Grandes cidades, tais como Londres na Inglaterra, Seattle nos Estados Unidos e Toronto no Canadá, implantaram nos últimos anos políticas de incentivo ao uso de telhados verdes, jardins verticais e demais formas de vegetação, a fim de aumentar a superfície vegetada em suas áreas urbanas e, assim, minimizar seu impacto ambiental.

Da mesma forma, campanhas nacionais no Japão e em Cingapura, incentivam pesquisas e aplicações dos jardins verticais como forma de redução no consumo energético para climatização (PECK et al, 2007; SHARP et al., 2008). Especificamente sobre a tipologia das cortinas verdes, um dos exemplares mais significativos 
construídos com esta técnica localiza-se no Chile e foi projetado pelo arquiteto Enrique Browne, ainda na década de 90 do século passado.

O Edifício Consorcio em Santiago possui fachadas envidraçadas, porém protegidas do excesso de sol pelo uso da vegetação trepadeira, que se desenvolve em grandes floreiras e fixa-se em suportes metálicos afastados das aberturas. Além do sombreamento, regulado pela densidade da folhagem que varia segundo as estações do ano, a vegetação promove correntes de ar pelo "efeito chaminé" e o resfriamento da fachada (Figura 6).

O comportamento energético do edifício foi avaliado por Reyes apud Browne (2007), onde foi realizada uma comparação entre dois pavimentos do edifício: um sem a vegetação como elemento de sombreamento e outro com a cortina verde.

$\mathrm{O}$ resultado mostrou que o pavimento protegido consome $35 \%$ menos de energia, como uma redução de $25 \%$ nos custos.

Outro aspecto relevante da utilização da vegetação como componente do projeto é o efeito visual interessante e as transformações que a fachada apresenta ao longo dos anos e das variações sazonais. Ao contrário dos materiais de construção usuais, que se deterioram com o tempo ou que são substituídos por novas tecno- logias, a vegetação se desenvolve, cresce e revigora a imagem do edifício com o passar dos anos (BROWNE, 2007).

Outro exemplo de edificação que utiliza as cortinas verdes é o Edifício Ex Ducati, na Itália, projetado pelo arquiteto Mario Cucinella e executado em 2006.

A fachada principal e as laterais são cobertas com uma espécie trepadeira que cresce auxiliada por uma grelha de aço. Esta solução de fachada, segundo o próprio arquiteto, cria a aparência de jardins verticais suspensos e remete aos edifícios tradicionais cobertos com hera (UFFELEN, 2011).

A vegetação cresce a partir do solo e também em jardineiras dispostas ao longo do segundo pavimento, onde forma na varanda dos escritórios um espaço permeável ao ar e à luz, além de permitir o contato dos ocupantes com a natureza (Figura 7).

Mais recentemente, em Cingapura, o escritório WOHA Arquitetos projetou uma edificação destinada a uma escola especializada em artes visuais e performativas. $\mathrm{O}$ conceito adotado no projeto prioriza a ventilação e luz natural em todos os espaços, revelando os novos paradigmas da arquitetura em Cingapura, voltada aos preceitos do bioclimatismo e da sustentabilidade. 


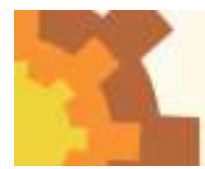

\section{ReLAInEF}

FIGURA 6: EDIFÍCIO CONSORCIO SANTIAGO DETALHE DAS CORTINAS VERDES E COMPORTAMENTO TÉRMICO DO EDIFÍCIO
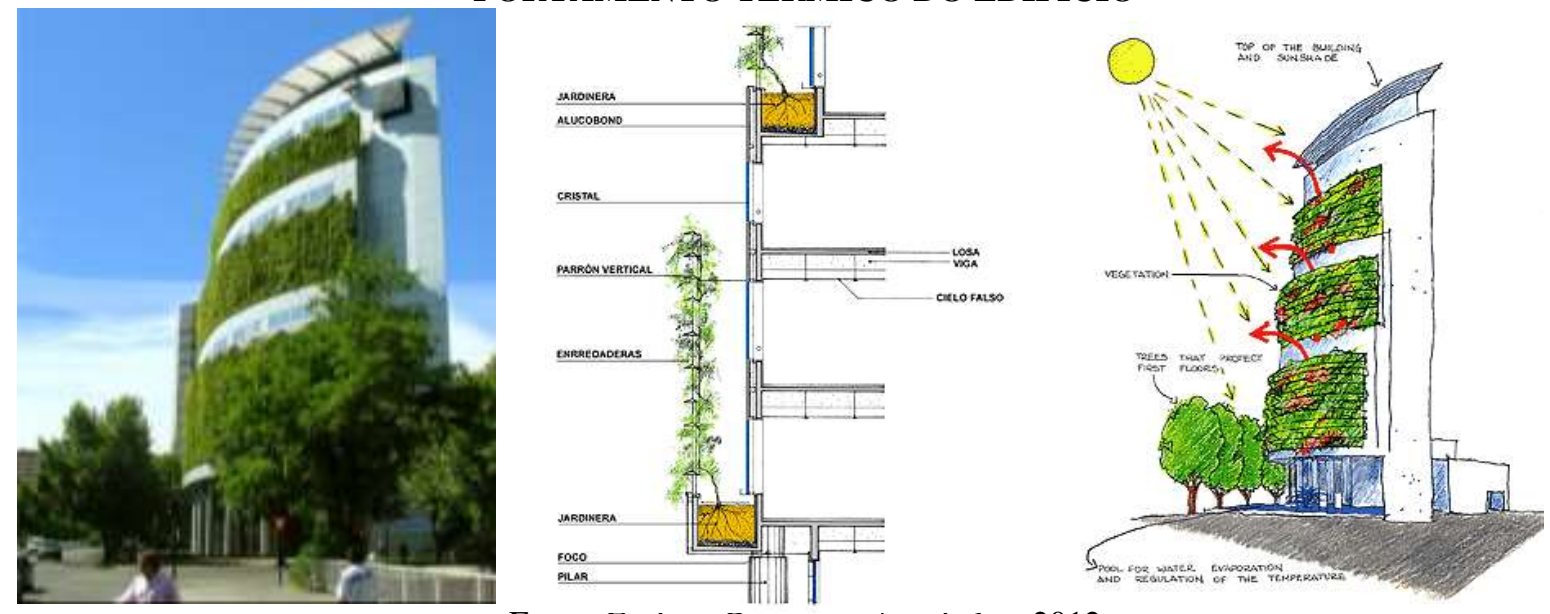

Fonte: Enrique Browne y Asociados, 2012

Uma das características plásticas e funcionais marcantes no projeto é a presença das cortinas verdes, em todas as fachadas do edifício (Figura 8). Cingapura está incentivando a aplicação dos jardins verticais na cidade e nas edificações, como estratégia de redução no consumo energético com climatização artificial. A vegetação atua como filtro ambiental, contra o excesso de luz, calor e poluentes, além de pro- mover o resfriamento evaporativo da ventilação que entra nos espaços.

Estes são apenas alguns exemplos de prédios já executados com a utilização das cortinas verdes, sendo que, a cada dia, verificam-se inúmeros projetos em fase de estudos, em todas as regiões do planeta, o que dá uma previsão do quanto sua aplicação tende a crescer nos próximos anos.

\section{FIGURA 7: FACHADA COM VEGETAÇÃO TREPADEIRA E VARANDAS DOS ESCRITÓRIOS}
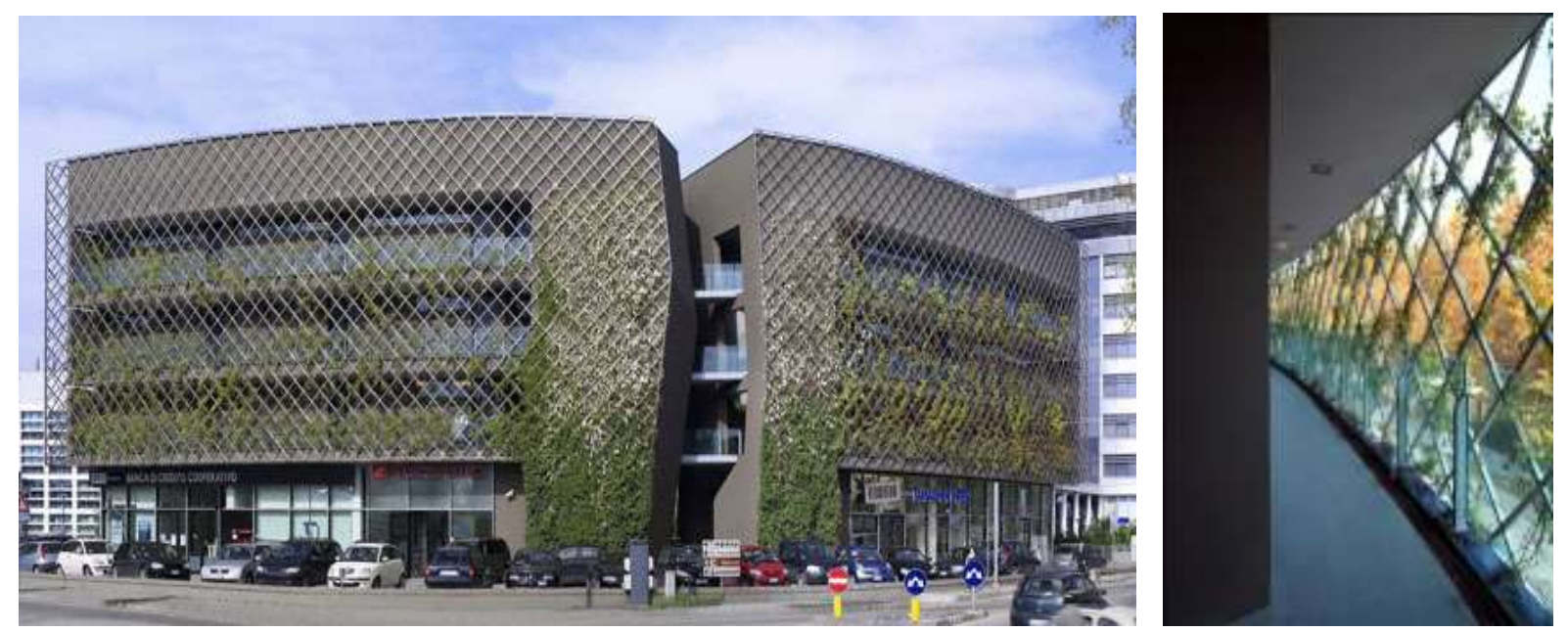

Fonte: Mario Cucinella Architects, 2012 


\section{FIGURA 8: O EDIFÍCIO EM CINGAPURA E DETALHE DAS CORTINAS VERDES ATUANDO NO SOMBREAMENTO DOS ESPACOS}
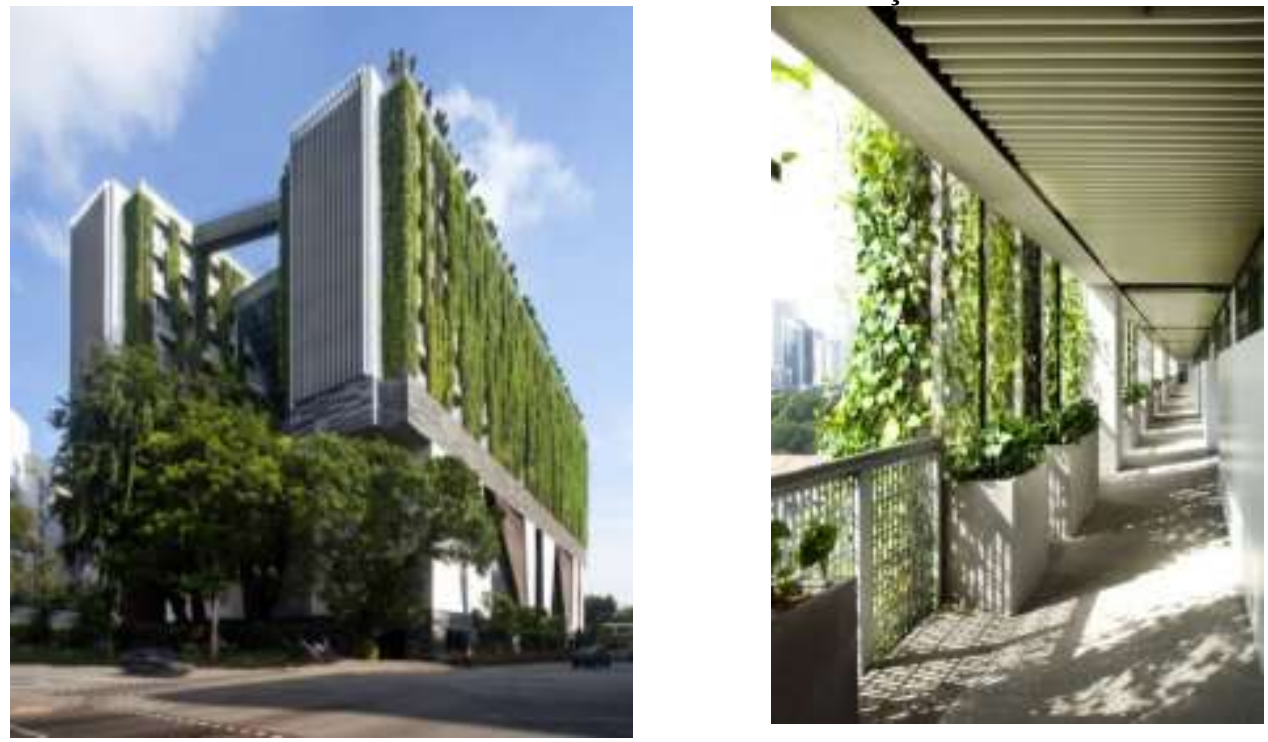

Fonte: Archdaily, 2012

\section{Considerações finais}

O uso da vegetação representa uma forte estratégia para o futuro das cidades, já que são inúmeros os benefícios proporcionados pelo aumento do verde nos centros urbanos. Os benefícios ambientais estão relacionados aos efeitos sobre a radiação solar, purificação do ar, retenção de poluentes e umidificação.

Os agentes combinados podem representar economia no consumo de energia para climatização da edificação, tornando naturalmente o micro-clima mais agradável. Por outro lado, os benefícios sociais, estéticos e psicológicos também representam uma importante justificativa para o aumento do verde e qualificação dos ambientes de trabalho, uma vez que o bem estar do ser humano está intimamente ligado ao seu contato com a natureza.

Neste contexto, novas formas de revegetação, incorporadas na edificação, representam uma importante alternativa para a escassez de áreas urbanas disponíveis para parques e praças.

Este é o caso dos jardins verticais, onde as fachadas das edificações são aproveitadas como suporte para o desenvolvimento da vegetação e, particularmente, das cortinas verdes que foram exemplificadas neste trabalho.

Este tipo de fachada verde, além de proporcionar maior contato com a vegetação, representa uma técnica de controle da radiação solar e amenização do microclima interno das edificações, evitando o uso excessivo de climatização artificial.

Através dos exemplos arquitetônicos apresentados, que utilizam as cortinas verdes enquanto elemento de proteção solar e, ao mesmo tempo, de composição arquitetônica, podemos observar o quanto promissor pode ser a adoção desta estratégia natural e de baixo impacto 
ambiental.

Ao mesmo tempo em que seu uso vem sendo gradativamente explorado a nível mundial, constata-se que ainda existem poucos estudos científicos que discutam suas potencialidades e fragilidades, seu desempenho como elemento de proteção solar e auxiliem os projetistas para a aplicação prática das cortinas verdes em arquitetura.

No Brasil, a utilização das cortinas verdes ainda é insipiente, com poucos exemplares, a maioria ainda em fase projetual. No âmbito científico, o cenário nacional é ainda mais defasado, o que justifica a realização de investigações sobre seu uso, sobre sua aplicabilidade para a realidade tecnológica, cultural e climática de nosso país.

\section{Referências}

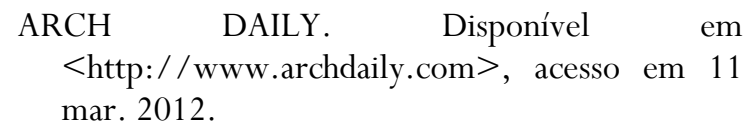
<http://www.archdaily.com>, acesso em 11 mar. 2012.

BROWNE, E. El Edificio "ConsorcioSantiago” 14 Años Después. Santiago, 2007. Disponível em: <http://www.ebrowne.cl>, acesso em: 10 jul. 2010.

CANTUÁRIA, G. A. C. Microclimatic impact of vegetation on building surfaces. MA Dissertation - Environment and Energy Studies Programme. London : A. A. School of Architecture, 1995.

DE LA TORRE, J, M, O. La vegetación como instrumento para el control microclimático. 1999. Tese (doutorado). Programa de Doctorado Ámbits de Recerca de la Construcció i l'Energía a l'Arquitectura. Universitat Politècnica de Catalunya, Barcelona, 1999.

DUNNETT, N. \& KINGSBURY, N. Planting Green Roofs and Living Walls. Portland:
Timber Press, 2004.

ENRIQUE BROWNE Y ASOCIADOS. Disponível em <http://www.ebrowne.cl>, acesso em 18 fev. 2012.

GSKY PLANT SYSTEM. Disponível em <http://www.g-sky.com>, acesso em 02 ago. 2012.

JOHNSTON, Jacklyn \& NEWTON, John. Building Green: a guide to using plants on roofs, walls and pavements. London, 2004.

KÖHLER, Manfred. Fassaden-und dachbegrünung. Stuttgard: Ulmer, 1993.

KÖHLER, M. Green facades - a view back and some visions. Urban Ecosyst, n. 11, p. 423436, 2008.

KWOK, Alison G; GRONDZIK, Walter T. Manual de arquitetura ecológica. Porto Alegre: Bookman, 2013.

LYLE, J. T. Regenerative design for sustainable development. New York: John Wiley \& Sons, 1994.

MARIO CUCINELLA ARCHITECTS. Disponível em <http://www.mcarchitects.it>, acesso em 11 mar. 2012.

MASCARÓ, L. \& MASCARÓ, J. Vegetação Urbana. Porto Alegre: +4 Editora, 2005.

PECK, S.; et al. Greenbacks from Green Roofs: Forging a New Industry in Canadá. In: Research Highlight - Technical Series 01-101. Ottawa: Canada Mortgage and Housing Corporation, 2007. Disponível em: <http:/ / www.cmhc-

schl.gc.ca/odpub/pdf/62665.pdf>, acesso em: 7 jan. 2012

PÉREZ, G. Façanes vegetades: estudi del seu potencial com a sistema passiu d'estalvi d'energia, en clima mediterrani continental. Tese (doutorado). Programa de Doctorado Ámbits de Recerca de la Construcció i l'Energía a l'Arquitectura. Universitat Politècnica de Catalunya, Barcelona, 2010.

SHARP, R.; et al. Introduction to Green Walls: Technology, Benefits \& Design. In: 
Green Roofs for Healthy Cities, 2008. Disponível em <http://www.greenroofs.net>, acesso em 08 out. 2009.

STYLEPARK. Disponível em <http://www.stylepark.com/en/architecture/ anatomy-of-a-green-facade/299143>, acesso em 02 ago. 2012.

UFFELEN, C. V. Façade Greenery: contemporary landscaping. Ed. Braun, 2011. 